\title{
Correction to: Social Mobility and Life Satisfaction across European Countries: A Compositional Perspective on Dissociative Consequences of Social Mobility
}

\author{
Jasper Dhoore ${ }^{1}$ (D) Stijn Daenekindt ${ }^{1,2} \cdot$ Henk Roose $^{1}$
}

Published online: 16 September 2021

(c) Springer Nature B.V. 2021

Correction to: Social Indicators Research (2019) 144:1257-1272 https://doi.org/10.1007/s11205-019-02083-2

In the original publication, due to a typesetting error, several decimal points were omitted from Table 2. The correct version is presented in this correction.

The original article can be found online at https://doi.org/10.1007/s11205-019-02083-2.

Jasper Dhoore

Jasper.Dhoore@ugent.be

1 Department of Sociology, Ghent University, Korte Meer 5, 9000 Ghent, Belgium

2 Department of Public Administration and Sociology, Erasmus University Rotterdam, P.O. Box 1738, 3000 DR Rotterdam, The Netherlands 
Table 2 Parameter estimates from the Diagonal Reference Model for dependent life satisfaction across countries categorized according to downward mobility rates and upward mobility rates

\begin{tabular}{lllll}
\hline Country groups according & Lowest quarter & Second quarter & Third quarter & Highest quarter
\end{tabular}
to downward mobility rates

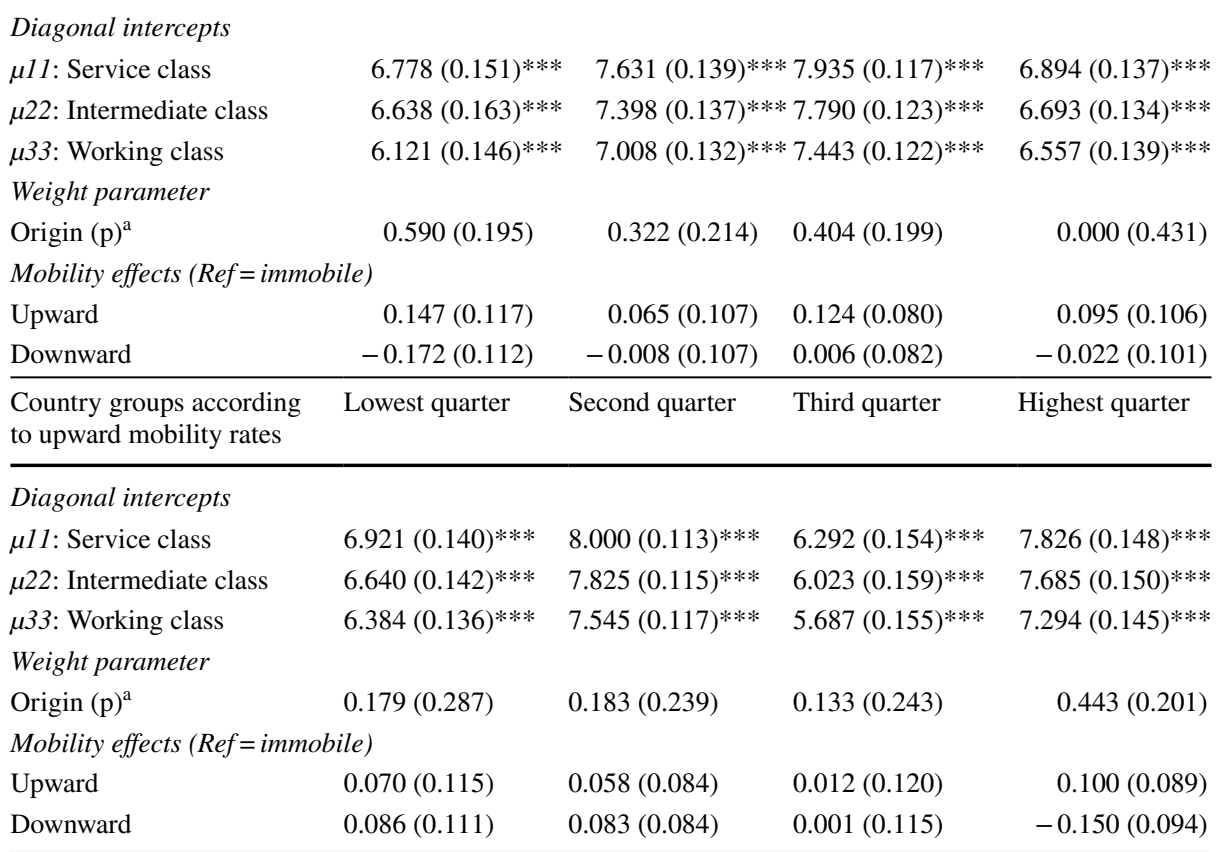

Analyses performed using SPSS 24; Weighted analyses; Selected age $\geq 30$; ${ }^{a}=$ None of the weight parameters are significantly different from 0.5 based on the $95 \%$ confidence interval; All models are controlled for gender, age, employment status and country dummies

$* p<0.05 ; * * p<0.01 ; * * * p<0.001$

Publisher's Note Springer Nature remains neutral with regard to jurisdictional claims in published maps and institutional affiliations. 